\title{
A metodologia Lego® Serious Play® como estratégia para promover a autonomia e melhorar os resultados no processo de aprendizagem no ensino superior
}

The Lego ${ }^{\circledR}$ Serious Play ${ }^{\circledR}$ methodology as a strategy to promote autonomy and improve results in the learning process in higher education

La metodología Lego ${ }^{\circledR}$ Serious Play ${ }^{\circledR}$ como estrategia para promover la autonomía y mejorar los resultados en el proceso de aprendizaje en la educación superior

Nedisson Luis Gessi ORCID: https://orcid.org/0000-0002-4508-2826 Fundação Educacional Machado de Assis, Brasil E-mail: nedisson@fema.com.br

Juliane Colpo

ORCID: https://orcid.org/0000-0001-7798-6275 Fundação Educacional Machado de Assis, Brasil E-mail: jcolpo@fema.com.br

Bianca Tams Diehl

ORCID: https://orcid.org/0000-0003-3449-6801 Fundação Educacional Machado de Assis, Brasil E-mail: bianca@fema.com.br

Denise Felber Chaves ORCID: https://orcid.org/0000-0002-7993-8645 Fundação Educacional Machado de Assis, Brasil E-mail: denisef@fema.com.br

Marilei de Fátima Kovatli ORCID: https://orcid.org/0000-0001-9134-181X Fundação Educacional Machado de Assis, Brasil E-mail: marilei_gti@fema.com.br

Antonio Roberto Lausmann Ternes ORCID: https://orcid.org/0000-0003-4464-9007 Fundação Educacional Machado de Assis, Brasil E-mail: antonioternes@gmail.com

\begin{abstract}
Resumo
O modo como está estruturada tanto a Escola quanto a Universidade, atualmente, evidencia um modelo de educação que existe há mais de um século. No entanto, esse mesmo modelo, se mostra incapaz de sustentar os novos desafios da sociedade contemporânea. Reforça-se, assim, a necessidade do desenvolvimento e a aplicação de novas metodologias e métodos de ensino, que favoreçam a mudança do modelo mental dominante, para o pensamento sistêmico, a autonomia, a inovação e a solução de problemas reais que motivem os aprendentes para uma aprendizagem efetiva. A metodologia Lego ${ }^{\circledR}$ Serious Play ${ }^{\circledR}$ cumpre essas funções, porém precisa ser compreendida e utilizada. Com base nesse contexto, o presente estudo tem por objetivo compreender como a metodologia Lego ${ }^{\circledR}$ Serious Play ${ }^{\circledR}$ pode contribuir para a qualificação da autonomia e, em consequência, dos resultados no processo de aprendizagem em ambientes de aprendizagem ativa no ensino superior, uma vez que essa metodologia é totalmente inovadora e disruptiva, proporciona grandes ganhos de engajamento e de produtividade dos aprendentes envolvidos, além de potencializar as competências de criatividade, de comunicação, de cooperação e de resolução de problemas complexos. O presente estudo assume uma perspectiva metodológica alicerçada no método da pesquisa-ação; em relação aos procedimentos técnicos utilizados, destaca-se a pesquisa bibliográfica e o estudo de caso; quanto ao método de abordagem optou-se pelo hipotéticodedutivo. Conclui-se que a metodologia Lego ${ }^{\circledR}$ Serious Play ${ }^{\circledast}$ surge como uma alternativa para contribuir na melhoria dos resultados no processo de aprendizagem em ambientes de aprendizagem ativa no ensino superior. Tal metodologia estimula a autonomia, o pensamento sistêmico e a transdisciplinaridade, nas quais o aprendente precisa conhecer o 'todo', desenvolvendo uma visão sistêmica, holística e global dos fatos.
\end{abstract}

Palavras-chave: Lego ${ }^{\circledR}$ Serious Play ${ }^{\circledR}$; Ludicidade; Autonomia; Aprendizagem; Inovação; Metodologia.

\footnotetext{
Abstract

The way in which both the School and the University are currently structured shows a model of education that has existed for over a century. However, this same model is unable to sustain the new challenges of contemporary society.
} 
This reinforces the need for the development and application of new teaching methodologies and methods, which favor a change from the dominant mental model to systemic thinking, autonomy, innovation and the solution of real problems that motivate learners for effective learning. The Lego ${ }^{\circledR}$ Serious Play ${ }^{\circledR}$ methodology fulfills these functions, but it needs to be understood and used. Based on this context, this study aims to understand how the Lego® Serious Play® methodology can contribute to the qualification of autonomy and, as a consequence, of the results in the learning process in active learning environments in higher education, since this methodology is totally innovative and disruptive, provides great gains in engagement and productivity of the learners involved, in addition to enhancing skills in creativity, communication, cooperation and solving complex problems. The present study takes a methodological perspective based on the action research method; in relation to the technical procedures used, the bibliographical research and the case study stand out; as for the method of approach, the hypothetical-deductive method was chosen. It is concluded that the Lego® Serious Play® methodology appears as an alternative to contribute to improving the results of the learning process in active learning environments in higher education. Such methodology encourages autonomy, systemic thinking and transdisciplinarity, in which the learner needs to know the 'whole', developing a systemic, holistic and global view of the facts.

Keywords: Lego® Serious Play®; playfulness; Autonomy; Learning; Innovation; Methodology.

\section{Resumen}

La forma en que se estructuran actualmente tanto la Escuela como la Universidad muestra un modelo de educación que existe desde hace más de un siglo. Sin embargo, este mismo modelo es incapaz de sostener los nuevos desafíos de la sociedad contemporánea. Esto refuerza la necesidad del desarrollo y aplicación de nuevas metodologías y métodos de enseñanza, que favorezcan el cambio del modelo mental dominante al pensamiento sistémico, la autonomía, la innovación y la solución de problemas reales que motiven a los educandos a un aprendizaje efectivo. La metodología Lego $\circledR$ Serious Play ${ }^{\circledR}$ cumple estas funciones, pero es necesario comprenderla y utilizarla. A partir de este contexto, este estudio tiene como objetivo comprender cómo la metodología Lego® Serious Play® puede contribuir a la calificación de la autonomía y, como resultado, los resultados en el proceso de aprendizaje en entornos de aprendizaje activo en la educación superior, ya que esta metodología es totalmente innovador y disruptivo, proporciona grandes ganancias en el compromiso y la productividad de los estudiantes involucrados, además de mejorar las habilidades en creatividad, comunicación, cooperación y resolución de problemas complejos. El presente estudio toma una perspectiva metodológica basada en el método de investigación-acción; en relación a los procedimientos técnicos utilizados, se destacan la búsqueda bibliográfica y el estudio de caso; en cuanto al método de aproximación, se eligió el método hipotético-deductivo. Se concluye que la metodología Lego® Serious Play® aparece como una alternativa para contribuir a mejorar los resultados del proceso de aprendizaje en entornos de aprendizaje activo en la educación superior. Dicha metodología fomenta la autonomía, el pensamiento sistémico y la transdisciplinariedad, en los que el alumno necesita conocer el "todo", desarrollando una visión sistémica, holística y global de los hechos.

Palabras clave: Lego® Serious Play®; Lúdico; Autonomía; Aprendiendo; Innovación; Metodología.

\section{Introdução}

Para alcançar melhores resultados a aprendizagem ativa requer ambientes apropriados, os quais são possíveis por meio da implementação de estratégias nas quais o aprendente é agente e autor do processo de aprendizagem. Tais estratégias têm sido desenvolvidas de forma mais intensa nas últimas décadas do século XX, onde o aprendiz passa ser o agente do processo de aprendizagem (Novaes et al., 2021).

Os ambientes devem promover a aprendizagem baseada na investigação de conteúdos autênticos e, na medida do possível, encorajar as habilidades de liderança, de autogestão e de autoconhecimento dos aprendentes. Por atividades de autodesenvolvimento, promover a aprendizagem colaborativa para construção de comunidades de aprendizado, propiciar um ambiente dinâmico por meio da aprendizagem interdisciplinar, gerando atividades de alto impacto para uma melhor experiência de aprendizagem e, por fim, os ambientes de aprendizagem ativa efetivam-se como promotores da integração do conhecimento já existente com novos conhecimentos que possibilitem uma rica estrutura de compartilhamento entre os aprendentes (Silva, 2018). Portanto, o problema de pesquisa do presente estudo centra-se em compreender como a metodologia Lego ${ }^{\circledR}$ Serious Play ${ }^{\circledR}$ pode contribuir para tornar o sujeito aprendente autônomo do processo e fomentar a melhoria dos resultados no processo de aprendizagem em ambientes de aprendizagem ativa no ensino superior.

Justifica-se o desenvolvimento do estudo, face à importância e a necessidade das Instituições de Ensino Superior (IES) investirem em ambientes e em processos de aprendizagem ativa, o que torna visível que a Lego ${ }^{\circledR}$ Serious Play ${ }^{\circledR}$ surge como uma 
alternativa para contribuir na melhoria dos resultados no processo de aprendizagem, uma vez que a metodologia promove o psychological flow ${ }^{1}$, permitindo que os estudantes ganhem mais do processo de aprendizagem ao serem envolvidos, engajados e tendo prazer em participar. Justifica-se, também, uma vez que, há poucos estudos referentes a aplicabilidade da metodologia Lego ${ }^{\circledR}$ Serious Play ${ }^{\circledR 2}$ em âmbito acadêmico, além de ser recente a utilização dessa metodologia, tanto em ambientes empresariais e coorporativos quanto acadêmicos no Brasil.

Para tal, definiu-se com objetivo central do estudo compreender como a metodologia Lego ${ }^{\circledR}$ Serious Play ${ }^{\circledR}$ pode contribuir para o desenvolvimento da autonomia do aprendente, bem como melhoria dos resultados no processo de aprendizagem em ambientes de aprendizagem ativa no ensino superior. Para atingir o objetivo proposto, o presente estudo inicialmente pretende caracterizar os ambientes de aprendizagem ativa e demonstrar as suas contribuições para o processo de aprendizagem. Em um segundo momento, abordar as principais contribuições do lúdico em ambientes de aprendizagem ativa no ensino superior, entender a metodologia Lego ${ }^{\circledR}$ Serious Play ${ }^{\circledR}$ e de que forma pode contribuir para melhorar os resultados no processo aprendizagem, em ambientes de aprendizagem ativa. Por fim, apresentar casos concretos de aplicabilidade desta metodologia em ambientes de aprendizagem ativa de uma Instituição de Ensino Superior do Noroeste Gaúcho.

\section{Metodologia}

A pesquisa-ação definida, de acordo com a perspectiva de Thiollent (2009), é um tipo de pesquisa social com base empírica que é concebida e realizada em estreita associação com uma ação ou com a resolução de um problema coletivo em que os pesquisadores e os participantes estão envolvidos de modo cooperativo ou participativo.

De acordo com Fiorentini (2004), nessa metodologia de intervenção caminham juntas a prática investigativa, a prática reflexiva e a prática educativa. Já para Barbier (2004), a pesquisa-ação tem um papel tanto social quanto pedagógico e político. Essa metodologia é caracterizada pelo papel ativo dos pesquisadores junto aos sujeitos da pesquisa. Na pesquisa-ação acontecem, simultaneamente, o "conhecer” e o "agir”, uma relação dialética sobre a realidade social desencadeada pelo processo de pesquisa.

É importante ressaltar que a sequência metodológica para a execução dos processos de pesquisa-ação insere-se na concepção de educação libertadora, tendo como ponto de partida o diálogo e incentivando a participação dos setores populares na busca do conhecimento da realidade a fim de transformá-la (Pinto, Bosco, 1989).

Portanto, para que a pesquisa-ação possa trazer resultados produtivos, é necessário que o pesquisador e os participantes assumam posicionamentos corretos. Além disso, alguns pressupostos de natureza da pesquisa-ação devem ser incorporados, tais como, respeitar que o outro tem saberes, acreditar que o outro pode produzir saberes, que o outro pode ser pesquisador e ter clareza de que o conhecimento é construído pelo coletivo (Thiollent, 2009). O método de pesquisa-ação se enquadra no presente estudo, uma vez que, nas coletas de dados predominaram questionários e observação participante. A maneira escolhida para tratar os dados gerados foi a qualitativa, que tem como perspectiva de análise a explicação dos fenômenos que se apresentam na sociedade.

Assim, nesta pesquisa, pretende-se abstrair os aspectos qualitativos da prática realizada com a metodologia Lego ${ }^{\circledR}$ Serious Play ${ }^{\circledR}$ nos cursos superiores das Faculdades Integradas Machado de Assis, embora tais dados não excluam os quantitativos, uma vez que, segundo Minayo, “[...] os dados quanti-qualitativos se complementam, pois a realidade abrangida por eles interage dinamicamente, excluindo qualquer dicotomia." (Minayo, 2002, p. 22).

Em relação aos procedimentos técnicos utilizados, destaca-se a pesquisa bibliográfica, a partir de livros, de artigos

\footnotetext{
${ }^{1}$ psychological flow é um estado mental de operação em que a pessoa está totalmente imersa no que está fazendo, caracterizado por um sentimento de total envolvimento e sucesso no processo da atividade. Proposto pelo psicólogo Mihaly Csikszentmihalyi, o conceito tem sido utilizado em uma grande variedade de áreas do conhecimento (Kamei, 2014).

${ }^{2}$ Lego $^{\circledR}$ Serious Play ${ }^{\circledast}$ é uma marca registrada da Executive Discovery, uma empresa independente associada ao LEGO Group, que oferece consultoria visando incentivar o pensamento criativo (Kristiansen \& Rasmussen, 2015).
} 
publicados em revistas e de produções científicas em geral. Como instrumento para o estudo de caso apresenta-se um questionário semiestruturado. Para a análise e a interpretação dos dados, o método de abordagem utilizado foi o hipotético-dedutivo, visando explicar o fenômeno em curso, com procedimentos secundários de caráter histórico e comparativo (Gil, 2008).

\section{Referencial Teórico}

\subsection{Ambientes de aprendizagem ativa}

O modo como está estruturada tanto a Escola quanto a Universidade, atualmente, evidencia um modelo de educação que existe há mais de um século. No entanto, tal se mostra incapaz de sustentar os novos desafios da sociedade contemporânea.

Dessa forma, o Ensino Superior precisa romper com o modelo tradicional de ensino, que tem como premissa um viés conteudista, no qual o professor é um mero transmissor de informações, que é prática da maioria das Instituições de Ensino Superior no Brasil.

A base do atual modelo é "ouvir-entender-memorizar-repetir-exercitar". A estrutura curricular é fragmentada em disciplinas e pressupõe que, de algum modo, o estudante seja capaz de realizar a integração destes elementos, fato esse que na prática, efetivamente, não ocorre. A aprendizagem acontece de forma dinâmica, sendo ela caracterizada por diferentes vertentes psicológicas, entre elas a teoria Behaviorista que aponta a aprendizagem como um resultado entre as experiências vividas pelo ser humano e os estímulos do meio (Souza \& Silva, 2021).

Portanto, torna-se necessário pensar novos modelos para novos tempos, preocupados em facilitar a aprendizagem, minimizar o excesso de aulas expositivas, que segundo estudos demostraram baixo impacto de aprendizagem, mudar o foco do estudante de sujeito passivo para um sujeito autônomo, que seja capaz de aprender a aprender. Assim, percebe-se a necessidade de mudanças no modelo atual - que tem como foco a metodologia expositiva de ensino -, para metodologias ativas de aprendizagem, ou mudança do foco no ensino para o foco na aprendizagem, para atender os novos desafios da contemporaneidade.

A alternativa que muitas Instituições de Ensino Superior vêm utilizando é a de aderir ao modelo com viés na aprendizagem, sobretudo na aprendizagem ativa. Muitos estudos provaram que a aprendizagem ativa como estratégia promove níveis de conquista e de domínio do conteúdo, bem como sua aplicabilidade, que só é possível por meio de atividades que façam com que o estudante esteja participando ativamente do processo, de tal forma que ele próprio se torne agente de sua aprendizagem.

Isso significa construir conhecimentos sobre os conteúdos envolvidos nas atividades que realizam, além de desenvolver estratégias cognitivas, capacidade crítica, autonomia para aprender e reflexão sobre suas práticas, fornecem e recebem feedback. A literatura também tem usado o termo "aprendizagem ativa" para caracterizar situações de aprendizagem em que o estudante é ativo (Nunes, 2017).

Em um ambiente de aprendizagem ativa, o professor atua como orientador, um supervisor, um facilitador do processo de aprendizagem e não apenas como fonte única de informação e de conhecimento. Independentemente do método ou da estratégia usada para promover a aprendizagem ativa, é essencial que o aluno faça uso de suas funções mentais. Em outras palavras, a diferença fundamental que caracteriza um ambiente de aprendizagem ativa é a atitude ativa da inteligência, em contraposição à atitude passiva, geralmente associada aos métodos tradicionais de ensino (Barbosa \& Moura, 2014).

É interessante ressaltar, ainda, que tão importante como pensar no que está fazendo, é sentir o que está fazendo. A participação dos sentimentos deve ser vista como um fator relevante na fixação do conhecimento. Pode-se afirmar que o bom humor, a boa disposição e a alegria são os lubrificantes das engrenagens do entendimento e da aprendizagem. A aprendizagem é mais significativa com as metodologias ativas. Além disso, os estudantes que estão inseridos em ambientes de aprendizagem ativa adquirem mais confiança em suas decisões e na aplicação do conhecimento em situações práticas. Aprimoram o 
relacionamento com os colegas, aprendem a se expressar melhor oralmente e por escrito. Adquirem gosto para resolver problemas complexos e vivenciam situações que requerem tomar decisões por conta própria, reforçando a autonomia no pensar e no atuar (Peixoto, 2016).

Portanto, a contemporaneidade traz novos rumos para os ambientes de aprendizagem. Tanto professores quanto os demais profissionais da educação devem se questionar sobre a possibilidade da construção de um mundo diferente, impulsionado por uma educação transformadora, que pressupõe a valorização das diferenças e a não linearidade e fragmentação do conhecimento. Vislumbrar a importância de um aprendizado efetivo, no qual o estudante possa desenvolver a capacidade de agir a partir do conhecimento e das habilidades adquiridas, colocando-as em prática em diferentes contextos e situações, e gerar resultados efetivos a partir delas. A ludicidade no contexto da aprendizagem ativa no ensino superior torna-se uma aliada para o alcance da aprendizagem efetiva, a partir de ambientes de aprendizagem ativa.

\subsection{A ludicidade no contexto da aprendizagem ativa no ensino superior}

Primeiramente, faz-se necessário desmistificar a compreensão restrita de ludicidade como sendo ação recreativa ou de lazer. O lúdico inclui a recreação, mas não se limita a ela. Recreação é uma atividade lúdica externa, não é ludicidade. Ludicidade é um estado interno, uma atitude de quem vivencia uma experiência lúdica plenamente. Lazer também não é sinônimo de ludicidade. Lazer é o espaço/tempo no qual as atividades lúdicas se realizam. Como estado de ânimo, ludicidade é da ordem subjetiva do sujeito. Sustenta-se, assim, a ideia de que a didática é a arte de mediar. Mediar com arte. A dimensão lúdica que traz a linguagem artística para dentro da sala de aula representa um importante ganho para a área. Torna-se necessário idealizarse uma didática lúdica que seja vivenciada plenamente na sala de aula e seja estruturadora de saberes pedagógicos e didáticos necessários à profissão docente.

A criatividade e a autoria são fatores estruturantes de uma ação educativa lúdica. Nesse contexto, segundo Luckesi, "Uma prática educativa lúdica possibilitará a cada um de nós e a nossos educandos aprendermos a viver mais criativamente e, por isso mesmo, de forma mais saudável”. (Luckesi, 2004, p. 20). Inclui-se aqui a dimensão da arte como ingrediente indispensável ao ensino lúdico. Daí a necessidade de trabalhar, nas metáforas criativas, com a linguagem artística em suas diferentes nuanças.

Alguns teóricos contribuíram para que o lúdico pudesse ser utilizado na educação, dentro do processo de ensino e aprendizagem, dentre os quais destacam-se: Jean-Jacques Rousseau e Johann Heinrich Pestalozzi, no século XVIII; John Dewey, no século XIX; e no século XX, Maria Montessori, Lev Vygotsky e Jean Piaget.

Piaget (1986) relata que o símbolo lúdico estimula o desenvolvimento do pensamento sobre os objetos não existentes representados por símbolos. Segundo as teorias de Vygotsky, o ser humano se desenvolve a partir do aprendizado, que envolve a interferência direta ou indireta de outros seres humanos, sendo que a mediação faz a diferença, interferindo na relação de aprendizagem da criança e fazendo com que as funções psicológicas superiores se desenvolvam no ser humano. Cita que o jogo é um instrumento importante para esse desenvolvimento, uma vez que os jogos e suas regras criam nos estudantes uma zona de desenvolvimento proximal (ZDP), proporcionando desafios e estímulos para a busca de conquistas mais avançadas, ensinando, também, a separar objetos e significados.

Vygotsky explica que a zona de desenvolvimento proximal (ZDP) é o percurso que o ser humano faz até chegar a um nível de amadurecimento real, sendo chamado por ele de zona de desenvolvimento real (ZDR), que consiste na capacidade do ser humano realizar tarefas independentes. Ao utilizar o lúdico para o ensino da matemática o professor está mediando o aprendizado dos alunos que, a partir da ZDP pode efetivamente adquirir um conhecimento, proporcionando alterações em sua estrutura cognitiva.

Para D’ávila (2013), a ludicidade é uma força motriz que impregna primeiramente o professor, elevando seu estado de 
espírito para um sentimento de pro-atividade, de alegria interna e o impulsiona a ações desencadeadoras de aprendizagens. Nesse momento entra a ludicidade como princípio organizativo, isto é, estruturador de atividades criativas, articuladas aos conteúdos das disciplinas, que levam os estudantes a vivenciarem a experiência pedagógica sugerida tanto externa quanto internamente.

Nesse horizonte o uso de metáforas criativas constitui excelente expediente para a educação em qualquer nível de ensino, o que se mostra como uma grande contribuição do lúdico no processo ensino e de aprendizagem em ambientes de aprendizagem ativa. $\mathrm{O}$ estudante pode construir conexões com o objeto de conhecimento muito mais significativas quando o contexto que o envolve é lúdico, justamente por envolver emoções e sentimentos.

Outro fator contribuinte para o grau de imersão de uma experiência de aprendizagem é que, quanto mais o aluno se vê como responsável pelas ações de escolha, de manipulação, de decisão e de criação, mais imersão ele sente. Fala-se da capacidade gratificante de realizar ações significativas e de ver os resultados dessas ações e escolhas. Imersão está ligada à diversão, no sentido que se relaciona com a experiência a ser saboreada (Filatro \& Cavalcanti, 2018). E é nesse momento que a metodologia Lego Serious Play entra em cena reforçando a importância da ludicidade no contexto da aprendizagem ativa no Ensino Superior.

\subsection{A metodologia lego ${ }^{\circledR}$ serious play ${ }^{\circledR}$}

Pesquisas recentes comprovaram que as mãos estão conectadas com cerca de 70\% a 80\% das nossas células cerebrais. Nossos cérebros estão limitados em relação à quantidade de informações com a quais eles conseguem conscientemente lidar de uma só vez. Com ajuda de todas as conexões neurais em nossas mãos se sabe muito mais do que pensamos em determinado momento. Ao usar as duas mãos simultaneamente se engaja ambos os lados dos nossos cérebros (Mccusker, 2014).

Desta forma, a metodologia Lego ${ }^{\circledR}$ Serious Play ${ }^{\circledR 3}$ desbloqueia a mente do participante. Quando utilizamos nossas mãos na aprendizagem, dá-se um processo complicado gerando uma carga emocional poderosa. Como resultado, quando nós construímos com nossas mãos, nossos pensamentos e ideias tendem a ter maiores detalhes e são facilmente compreendidos e lembrados (Mccusker, 2014).

De acordo com a pesquisa de Hinthorne e Schneider (2012), a brincadeira séria é particularmente boa para melhorar a reflexão crítica, encorajar a troca de conhecimentos e promover a resolução inovadora de problemas. O brincar é onde os objetos são transformados e as situações do mundo real são vivenciadas na brincadeira. Oliveira (1997) destaca que para Vygotsky essa atividade tem relação direta com desenvolvimento: ao brincar, a criança cria uma zona de desenvolvimento proximal devido à elaboração de situações mais complexas, como dar significado a um objeto diferente da função real, bem como imitar um papel durante uma brincadeira. Nessa brincadeira de faz de conta, existem regras, uma vez que, para imitar um personagem, a criança preocupa-se em fazê-lo tal como é, conferindo a regra da brincadeira.

Assim, a brincadeira séria proporciona a construção de habilidades básicas (Skill Building), pois é no momento em que se abre oportunidade para construir e abordar de forma crucial histórias que se relacionam com as experiências vividas. Além das perspectivas pessoais, que criam um espaço seguro no tempo para que as pessoas compartilhem seus pensamentos internos com os outros. À medida que as pessoas constroem e descontroem com o LEGO ${ }^{\circledR 4}$, elas também estão construindo em suas mentes. As atividades da brincadeira séria permitem questões e respostas e uma reflexão crítica que afeta tanto a forma quanto a função do brincar (Hinthorne \& Schneider, 2012).

A Metodologia Lego ${ }^{\circledR}$ Serious Play ${ }^{\circledR}$ foi desenhada para explorar e lidar com oportunidades e problemas concretos em tempo real. Foi concebida como ferramenta interativa para resolução de problemas, desenvolvida especificamente para ajudar a

\footnotetext{
${ }^{3}$ Lego ${ }^{\circledR}$ Serious Play ${ }^{\circledR}$ é uma marca registrada da Executive Discovery, uma empresa independente associada ao LEGO Group, que oferece consultoria visando incentivar o pensamento criativo (Kristiansen \& Rasmussen, 2015).

${ }^{4}$ A LEGO $^{\circledR}$ é uma empresa privada com sede em Billund, Dinamarca. As peças ou blocos LEGO fazem parte do sistema LEGO, que essencialmente significa que eles podem ser facilmente combinados de inúmeras maneiras - e tão facilmente desmontados. Quanto mais peças LEGO você tem, mais fértil sua criatividade pode se tornar. As configurações das peças e dos pinos e as minifiguras são marcas do Grupo LEGO ${ }^{\circledR}$ (Legobrasil, 2019).
} 
solucionar de forma criativa problemas de negócios e de comunicação. Pois, o uso de ferramentas práticas e criativas têm se mostrado útil em auxiliar no processo de ideação, de análise de risco, de comunicação e de colaboração (Isaksen, 2007).

Um dos pilares da metodologia é a etapa ou a parte da construção de modelos utilizando as peças/blocos LEGO, esses modelos apropriam-se muito da metáfora, o que ajuda a obter uma maior compreensão das variadas situações de determinado processo de análise profunda sobre um problema qualquer. Esse processo cria uma forma segura de que cada pessoa se envolva de maneira visual e interativa de pensar, testar e planejar, com riscos limitados (Isaksen, 2007).

Segundo Kristiansen e Rasmussen (2015), a metodologia Lego ${ }^{\circledR}$ Serious Play ${ }^{\circledR}$ é uma abordagem de pensamento, de comunicação e de resolução de problemas para tópicos que são reais. O foco do método não está nos blocos de $\mathrm{LEGO}^{\circledR}$, mas, sim, na história que eles criam por meio dos blocos. Os blocos e os modelos se tornam metáforas e a paisagem ou o cenário dos modelos viram histórias. Em seu livro Beyond the State, o professor do Instituto de Tecnologia de Massachusetts (MIT), Donal Schon (2000), argumenta que metáforas podem, na verdade, gerar maneiras radicalmente novas de entender as coisas. De acordo com o autor, metáfora é muito mais que simplesmente "linguagem floreada", ela pode ter um papel ativo, construtivo e criativo na cognição humana. Assim sendo, as metáforas oferecem ricas descrições de nossa realidade que podem desafiar pré-suposições e revelar novas possibilidades.

A metodologia incorpora ainda o compartilhamento de histórias e o movimento de artefatos em 3D (Blocos LEGO) e permite que as pessoas adquiriam uma compreensão mais profunda das ideias e dos conceitos. A ruptura e a reconstrução de ideias possibilita que os participantes desempenhem um papel na formulação coletiva de novas ideias. As ideias e as histórias compartilhadas permitem que as pessoas sintam que todos contribuíram com a sua história e, ao longo do processo, foram ouvidas e compreendidas pelos colegas (Bürgi \& Roos, 2003).

Este processo pega conceitos intangíveis e os traz para o presente, onde ideias concretas podem ser testadas e as soluções podem ser alteradas conforme a necessidade. Uma vez que os estudantes desenvolvem um modelo mental claro e preciso, eles podem elaborar metas e criar ações que estarão imediatamente prontas para serem implementadas. Como as novas estratégias são criadas em um mundo tridimensional pelos blocos LEGO, é plausível ajustar, em tempo real, conforme a necessidade, ou seja, é possível a cada reflexão melhorar o processo a partir da participação de todos no processo, inclusive é um recurso muito bom para trabalhar a competência de resiliência com os estudantes (Bürgi \& Roos, 2003).

Com os blocos LEGO, os estudantes podem construir suas ideias e depois demonstrar no modelo 3D, para explicar seus pensamentos aos demais envolvidos nas atividades. Os ouvintes podem ver o modelo e fazer perguntas, para esclarecer a compreensão, contrastando e comparando com seus pensamentos anteriores, permitindo a imersão de um novo tipo de entendimento. À medida que os estudantes quebram os modelos, eles também estão quebrando e liberando suas ideias e se movendo em direção a novas estruturas, que são compartilhadas entre o grupo participante. Em suma, nesse momento do processo se busca o engajamento, o desbloqueio de novos conhecimentos, que por sua vez desencadeia a ideia de quebrar o pensamento convencional, abrindo caminhos para a possibilidade de novas formas de resolver problemas complexos (Kristiansen \& Rasmussen, 2015).

Em se tratando de estudantes adultos, esse têm maior dificuldade de mudar seus modelos mentais apenas ouvindo. Eles precisam quebrar um modelo e reconstruí-lo com novas ideias. Essa conexão entre as estruturas mentais e a experiência prática tangível no mundo real é o que muda a dinâmica do processo. Quando as pessoas conseguem usar ferramentas externas como metáforas para testar seu conhecimento dentro de uma nova estrutura, elas conseguem criar novos modelos mentais de uma forma mais rápida e com mais confiança. Tais ferramentas incluem histórias, jogos e objetos físicos (Karp, 2005). Em uma atividade com Lego ${ }^{\circledR}$ Serious Play ${ }^{\circledR}$, os participantes desenvolvem e esclarecem seus modelos mentais.

Quanto à natureza ou pilar teórico científico, pode-se dizer que a metodologia Lego ${ }^{\circledR}$ Serious Play ${ }^{\circledR}$ está centrada em três elementos essenciais, que são: construtivismo, construcionismo e o psychological flow. 
Jean Piaget, o pai do construcionismo, talvez mais conhecido por sua teoria dos estágios de desenvolvimento infantil. Ainda mais fundamental que isto, foi a sua teoria de que crianças não adquirem simplesmente conhecimento pouco a pouco. Ao contrário, elas usam sua experiência no mundo para construir quadros coerentes e robustos chamados "estruturas do pensamento" (Piaget, 1986). As crianças não são apenas passivos observadores de experiências e informação, mas construtores ativos.

Segundo Piaget (1986), à medida que as estruturas mentais da criança se tornam competentes para lutar com novos problemas, ela é estimulada e desafiada por seu ambiente a encontrar novas soluções, o que, por sua vez, leva em direção a níveis mais elevados de desenvolvimento intelectual. Para Piaget (1987), o sujeito e o objeto formam um todo, cuja interação proporciona a construção e a reconstrução permanentes do conhecimento, bem como a formação de estruturas mentais cada vez mais complexas. Portanto, a teoria do construtivismo de Piaget explica que as pessoas não são aprendizes passivas, que recebem informações dos professores. Elas são aprendizes ativas, que precisam utilizar conhecimento do mundo real para que conceitos complexos sejam entendidos e façam sentido.

Saymour Papert, considerado pai do construtivismo, foi quem desenvolveu a teoria construtivista. O construtivismo vai um passo adiante. Papert acreditava que as pessoas são mais propensas a adquirir novos conhecimentos e ideias quando constroem coisas no mundo real. Ele ainda propôs que as pessoas utilizem artefatos para comunicar significado dentro de seus ambientes e que estas pessoas usem esse processo para resolverem problemas. Papert procurou criar um ambiente de aprendizagem mais favorável às teorias de Piaget. Ele enxergava os ambientes escolares convencionais como muito estéreis, muito passivos, muito dominados pela instrução; eles não providenciavam, nem promoviam, uma atmosfera que permitia às crianças serem construtoras ativas, que ele sabia que eram (Papert, 2008). Papert denominou sua teoria de "construtivismo". A teoria incluía tudo associado com o construtivismo de Piaget, mas foi um passo adiante. Segundo Papert se acreditarmos que retemos conhecimento como estruturas baseadas em nossa interação com o mundo, então nós podemos criar conhecimento mais rápido e melhor quando estamos engajados na construção de um produto, pois, para ele, "quando você cria no mundo você constrói a sua mente". Assim, o construcionismo incorpora e cria, por meio da teoria de Piaget sobre construtivismo, dois tipos de construção, que estão na verdade acontecendo aliadas, uma reforçando a outra. Quando pessoas constroem coisas, elas simultaneamente juntam teorias e estruturas de conhecimento em suas mentes. Então, esse novo conhecimento permite-lhes construir coisas ainda mais sofisticadas, isso porque, para Papert, o que aprendemos no processo de construir coisas que nós gostamos penetra muito mais profundamente em nosso subconsciente do que aquilo que qualquer um pode nos dizer (Papert, 1991).

A teoria do construtivismo explica como as pessoas constroem o conhecimento em suas cabeças, enquanto a teoria do construcionismo explica como elas adquirem e solidificam o conhecimento a partir das construções no mundo real. Por meio desse processo, Papert acreditava que as pessoas poderiam criar coisas que fossem tangíveis permitindo que outras pessoas pudessem ver, questionar, criticar e também utilizar para a sua própria compreensão. O valor dessas teorias é evidente dentro do processo interativo e prático baseado no uso das mãos (hands-on). Isso respalda um princípio central da metodologia Lego ${ }^{\circledR}$ Serious Play ${ }^{\circledR}$ : o aprendizado acontece, especialmente, quando criamos ativamente algo físico/concreto que é externo a nós (Kristiansen, Schulte \& Grientz, 2016).

Portanto, dentro do processo Lego ${ }^{\circledR}$ Serious Play ${ }^{\circledR}$, o construtor cria metáforas utilizando blocos de construção e dessa forma atribui significado aos modelos. As histórias, então, são formuladas e compartilhadas enquanto o construtor usa seu modelo para expandir seu pensamento à medida que compartilha informações e permite questionamentos dos outros. O construtivismo e o construcionismo são as duas teorias fundamentais que foram utilizadas para desenvolver a metodologia Lego ${ }^{\circledR}$ Serious Play ${ }^{\circledR}$ (Kristiansen, Schulte \& Grientz, 2016).

Por fim, o último elemento da metodologia é o psychological flow, que consistem em um estado mental de operação em que a pessoa está integralmente imersa no que está fazendo, caracterizado por um sentimento de total envolvimento e sucesso 
no processo da atividade. Proposto pelo psicólogo Mihaly Csikszentmihalyi, o conceito tem sido utilizado em uma grande variedade de áreas do conhecimento (Kamei, 2014). A ciência do Flow é completamente integrada à metodologia Lego ${ }^{\circledR}$ Serious Play ${ }^{\circledR}$ como chave mestra do aprendizado tanto do indivíduo quanto do grupo, assim torna-se impossível imaginar que a metodologia funcione sem os blocos LEGO ou sem integrar o conceito de Flow. Portanto, o Flow é uma condição na qual estamos completamente absortos em um jogo ou tarefa, perdemos nosso sentido de tempo e espaço, e utilizamos nosso potencial de aprendizado ao máximo (Kamei, 2014).

Visto os três elementos essenciais da metodologia Lego ${ }^{\circledR}$ Serious Play ${ }^{\circledR}$ percebe-se claramente que a metodologia proporciona para as pessoas a oportunidade de construir objetos que sejam metáforas de ideias, pensamentos e inovações, assim permitindo que outros vejam os modelos tridimensionais construídos e que possam ser questionados e desafiados. Esse processo envolve iniciativa e liberdade, além de sustentação para autonomia intelectual. O processo permite o desenvolvimento de um modelo mental claro e preciso. Uma vez que, é altamente visual, junto com o relato de histórias que ajuda as pessoas a esclarecerem suas ideias e também seus pensamentos e poderem expressar suas opiniões, a metodologia Lego ${ }^{\circledR}$ Serious Play ${ }^{\circledR}$ tem sido uma ferramenta útil no campo coorporativo podendo ser utilizado de forma estratégica no processo de ensino aprendizagem em ambientes ativos no ensino superior.

Desta forma, essa metodologia facilita o desenvolvimento de metas e de ações que ficam imediatamente prontas para implementação, além de permitir uma discussão altamente colaborativa e interativa, onde as ideias podem ser construídas e descontruídas da mesma forma que nossos cérebros se conectam e se desconectam das ideias, conceitos e pensamentos. As peças de LEGO dão aos nossos cérebros uma forma tátil de processar as informações e tomar decisões na resolução de problemas complexos, sempre prezando pela participação (engajamento) de todos no processo, sendo essa uma das premissas base da metodologia.

\section{Resultados e Discussão}

A partir da referencial teórico visto e tendo como um dos objetivos do estudo trazer casos concretos de aplicabilidade da metodologia Lego ${ }^{\circledR}$ Serious Play ${ }^{\circledR}$ em ambientes de aprendizagem ativa no ensino superior, aqui apresenta-se o caso de uma IES localizada no Município de Santa Rosa, no Noroeste do Estado do Rio Grande do Sul. A IES objeto do estudo é a FEMA Fundação Educacional Machado de Assis, que conta, atualmente, com 6 cursos superiores: Administração, Direito, Ciências Contábeis, Enfermagem, Gestão de Recursos Humanos e Gestão da Tecnologia da Informação.

O estudo teve início no mês de agosto de 2018 com as turmas de Administração, Gestão de Recursos Humanos e Gestão da Tecnologia da Informação, oportunidade em que o pesquisador (Facilitador Certificado Lego ${ }^{\circledR}$ Serious Play ${ }^{\circledR}$ ), juntamente com os docentes Juliane Colpo, Liliana Gessi e Lauri Heckler, que aplicaram a metodologia com objetivo experimental e já nos primeiros momentos das atividades foi perceptível o engajamento e a participação de todos. A atividade estimulou a imaginação, a criatividade e o trabalho cooperativo dos participantes, fomentando a autonomia cognitiva de todos. O percurso mobilizou o surgimento do projeto "FEMA LEGO ${ }^{\circledR}$ SERIOUS PLAY ${ }^{\circledR 5 " . ~}$

A partir da primeira intervenção decidiu-se averiguar, medir ou gerar indicadores para uma melhor compreensão da efetividade e do potencial da metodologia, sobretudo no que tange sua aplicabilidade, e de que forma seria possível aproveitá-la para inovar nos processos de aprendizagem em ambientes de aprendizagem ativa, uma vez que a FEMA vem há mais de dois anos investindo na formação docente e na utilização de metodologias ativas em seus ambientes de aprendizagem.

Assim, construiu-se um instrumento de pesquisa com 6 perguntas referentes às percepções dos estudantes acerca da atividade com uso da metodologia Lego ${ }^{\circledR}$ Serious Play ${ }^{\circledR}$. O instrumento foi assim constituído: 1) A atividade foi considerada por

${ }^{5}$ http://www.jornalnoroeste.com.br/noticias/educacao-cultura/projeto-fema-lego-serious-play https://portalplural.com.br/projeto-fema-lego-serious-play-umaproposta-inovadora/ http://www.jornalnoroeste.com.br/noticias/educacao-cultura/fema-estara-presente-no-lets-go-festival 
mim: (escolha de uma alternativa); 2) Sobre a significação dos conhecimentos trabalhados pelos professores: (escolha de uma alternativa); 3) A Metodologia utilizada ajudou na construção dos conhecimentos? (escolha de uma alternativa); 4) A partir da atividade prática, desenvolvi as seguintes competências: (escolha de múltiplas alternativas); 5) A referida atividade prática envolveu você como aluno, em que sentido? (escolha de uma alternativa); 6) Faça uma avaliação geral do processo (aberta descritiva). Além do instrumento foi realizada observação participante e relatos dos docentes envolvidos na referida prática.

A pesquisa foi realizada no período de setembro de 2018 a setembro de 2019, tendo como participantes docentes e discentes dos cursos de Administração com 38 estudantes, Ciências Contábeis com 35 estudantes, Direito com 50 estudantes, Gestão de RH com 23 estudantes e Gestão de TI com 20 estudantes, perfazendo um total de 166 estudantes e 4 docentes que trabalham nos referidos cursos.

O processo de aplicação da metodologia LSP $^{6}$ iniciava-se com o planejamento em conjunto com o docente envolvido, sendo que todo o processo é centrado na metodologia de sala de aula invertida. O conceito de sala de aula invertida vem da ideia de inverter a lógica tradicional de aula. Fazendo em casa o que é feito em sala, como assistir uma aula expositiva. E fazer em sala o trabalho que era feito em casa. Portanto, um dos principais objetivos da sala de aula invertida é desenvolver no aluno autonomia e autorregulação no seu processo de aprendizagem. A proposta do método é tornar as aulas menos expositivas e, assim, promover maior participação dos alunos no que está sendo desenvolvido (Bergmann \& Sams, 2017).

Dessa forma, os estudantes recebiam material de suporte antecipadamente e no início da aula eram disparadas as questões norteadoras (desafio) do problema, que deveriam buscar sanar utilizando-se do conteúdo prévio, por eles visto, e conjuntamente com as orientações do Facilitador $^{7}$, o que corresponde a primeira etapa da LSP. Posterior as orientações e as regras a serem seguidas, diga-se todas as regras, tem-se o tempo como variável fundamental na atividade, pois há sprint, entregas com tempo determinado para realizar as atividades.

Determinadas as regras pelo Facilitador, é dado início à construção do modelo da solução com blocos LEGO, que é a segunda etapa da metodologia. Após os tempos determinados, seguem as demais fases até a conclusão do processo, que acontece com a última etapa envolvendo uma reflexão final em conjunto com todos os participantes.

\footnotetext{
${ }^{6}$ Abreviatura de Lego ${ }^{\circledR}$ Serious Play ${ }^{\circledR}$

${ }^{7}$ O professor Dr. Nedisson Gessi é "Facilitador Lego ${ }^{\circledR}$ Serious Play ${ }^{\circledR ”}$ com Certificação Internacional, reconhecida pela LEGO ${ }^{\circledR}\left(\right.$ Certified by the Global $^{6}$

Federation of LSP Master Trainers).
} 
Figura 1 - Visão Macro da Metodologia LSP.

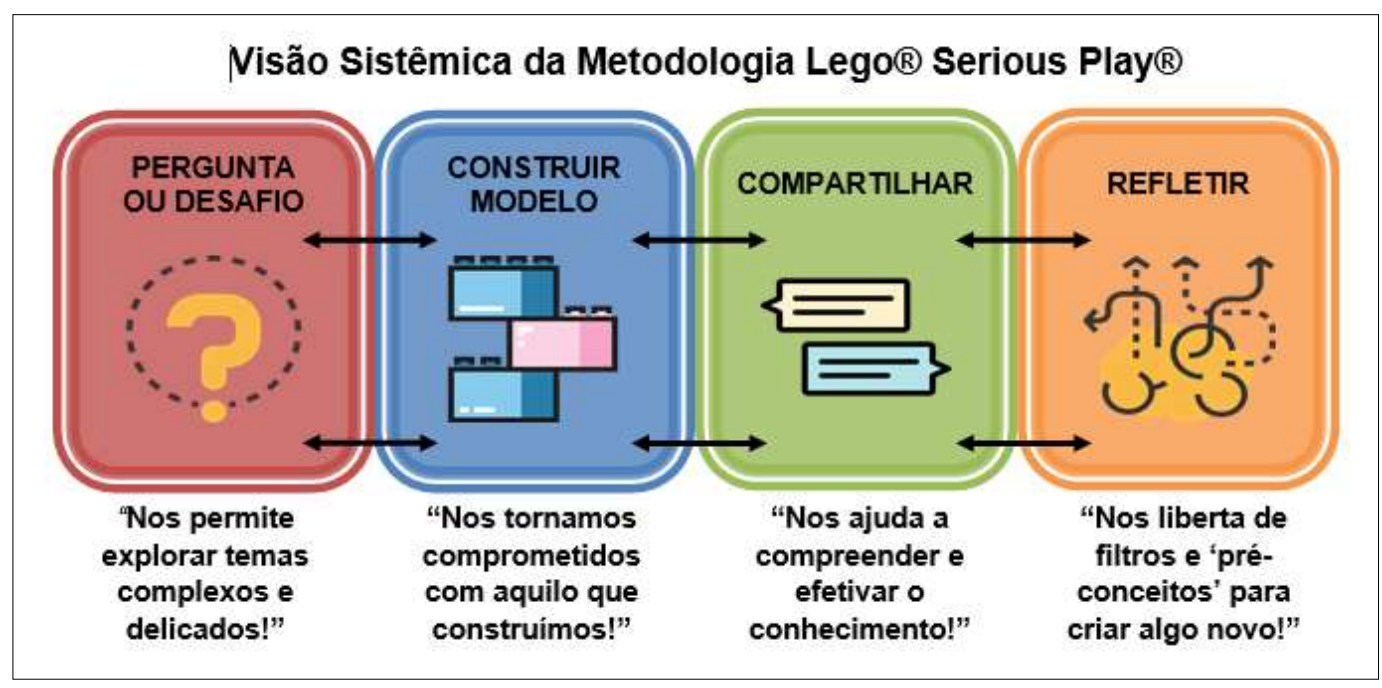

Fonte: Autores (2021).

A Figura 1 ilustra uma visão macro da Metodologia Lego ${ }^{\circledR}$ Serious Play ${ }^{\circledR}$ e adicionada a essa estrutura a ideia do Storytelling, além do Lúdico e da metáfora já vistos no embasamento teórico do presente estudo. No Storytelling, as pessoas pensam em formato de narrativas ou histórias e é dessa maneira que elas compreendem o mundo, por meio de personagens, de desejos e de motivações (Sutherland, 2014). O Storytelling é considerado uma metodologia ativa por trazer uma proposta de narrativa estruturada em uma sequência de fatos, que busca um estreitamento de sentidos e de emoções com o receptor da mensagem (Lopez, 2007). É a arte de elaborar e encadear cenas, dando-lhes um sentido envolvente que capte a atenção das pessoas e que enseje a assimilação de uma ideia central (Xavier, 2015).

Após a coleta de informações, por meio de um questionário eletrônico preenchido pelos estudantes, relatos dos docentes e das observações dos participantes, buscou-se tabular os dados para realizar a análise dos mesmos cruzando com os relatos dos docentes e com a pergunta aberta do questionário.

Figura 2 - Percepção dos Estudantes quanto as competências.

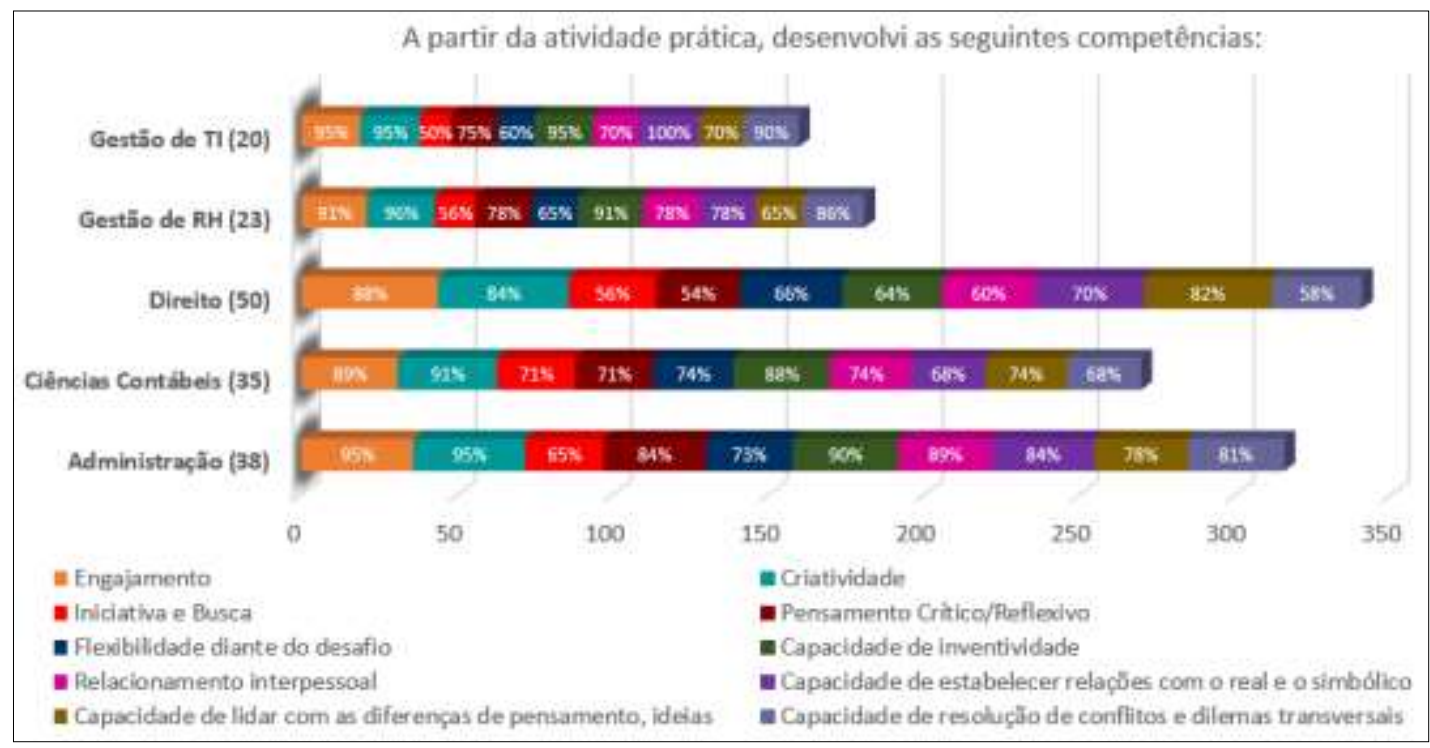

Fonte: Autores (2021). 
A Figura 2 ilustra, de forma sintetizada, a percepção dos estudantes quanto ao desenvolvimento ou o estímulo de competências, por meio da atividade realizada utilizando a metodologia LSP. A partir das observações juntamente com os relatos docentes e também a questão aberta, na qual foi questionado aos estudantes como eles avaliam de forma geral o processo envolvendo a metodologia LSP, constatou-se que, dentre as percepções elencadas pelos estudantes as competências de engajamento, de criatividade, de capacidade de inventividade, de capacidade de resolução de conflitos e de dilemas transversais, além da possiblidade de uma aula mais leve, divertida e ao mesmo tempo colocando em prática os conteúdos previamente vistos via plataforma eletrônica. Assim, optou-se em analisar as competências de uma forma geral, elencando as que predominaram em todos os cursos superiores, objeto desse estudo. Ainda, no tocante a percepção dos estudantes em relação a questão aberta, foi extremamente rica para análise, pois evidenciou-se a baixa aceitação das aulas expositivas e seus resultados, onde foi possível verificar nos trechos, em sua íntegra, a seguir da questão aberta:

E1: "Atividade muito proveitosa, nos deslocamos da produção escrita ao mundo prático da produção, a cooperação e alegria entre os colegas foi muito perceptível e os resultados de aprendizagem, com certeza, foram alcançados! Gratos pela oportunidade em ser a primeira turma de Direito a experimentar esse jeito inovador de aprender."

E2: "Achei interessante pois conseguimos desenvolver o trabalho em grupo, além disso sair um pouco da escrita e da leitura de todo dia para uma atividade diferente é muito importante para desenvolvermos a criatividade".

E3: "Achei muito bom, pois me ajudou a entender melhor o conteúdo"

E4: "O processo possibilitou uma interação mais efetiva com o tema estudado, já que utilizamos nosso conhecimento de forma dinâmica e atrativa. Além disso, teve espaço para trabalharmos nossa oralidade e o trabalho em equipe".

E5: "Foi muito proveitoso, além de ser uma maneira criativa de incentivar nossa criatividade. Gostei muito de participar"

Figura 3 - Percepção dos Estudantes quanto realização da atividade.

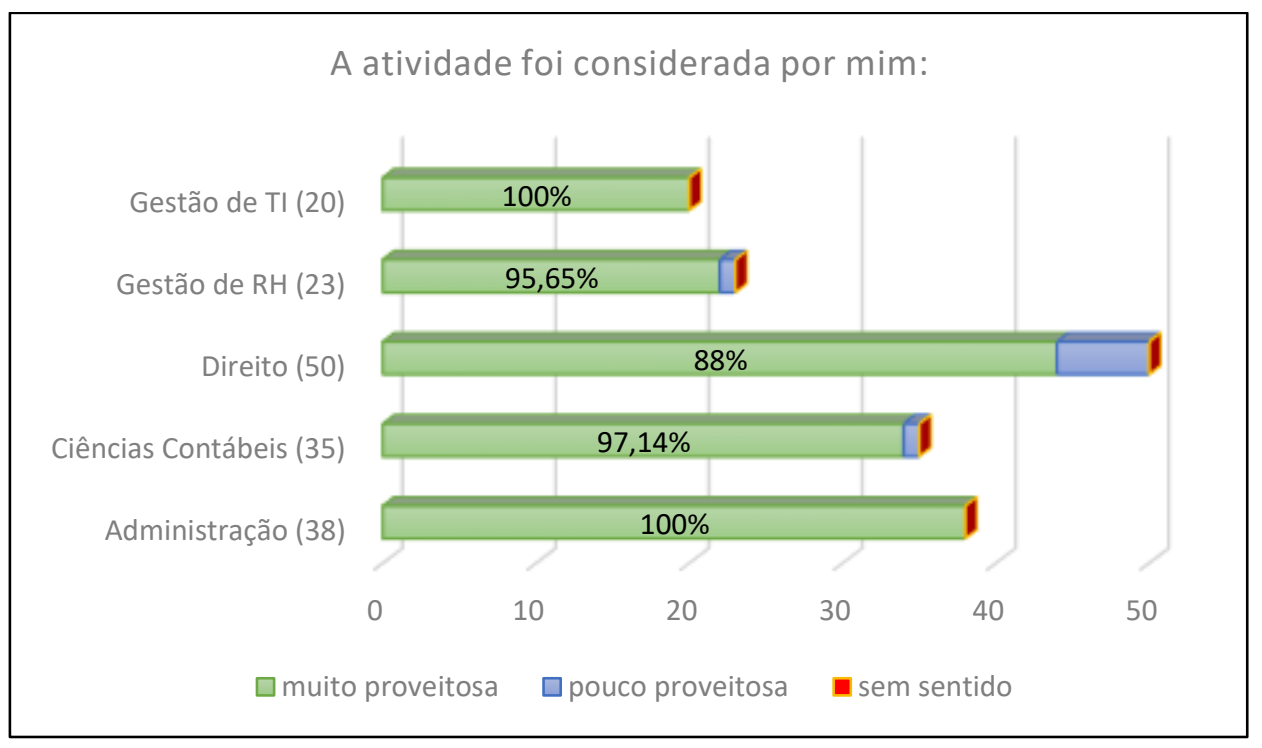

Fonte: Autores (2021).

Constatou-se que um número muito baixo de estudantes consideram a experiência vivenciada sem sentido ou pouco proveitosa, pois dos 166 estudantes, apenas 8 responderam que a atividade foi pouco proveitosa, desses 6 são estudantes do Curso de Direito, curso esse que ainda se utiliza muito de aulas expositivas e de métodos tradicionais de aprendizagem, o que se 
evidenciou na questão aberta quando a estudante expressa dizendo que "deslocamos da produção escrita ao mundo prático da produção".

E1: "Atividade muito proveitosa, nos deslocamos da produção escrita ao mundo prático da produção, a cooperação e alegria entre os colegas foi muito perceptivel e os resultados de aprendizagem, com certeza, foram alcançados! Gratos pela oportunidade em ser a primeira turma de Direito a experimentar esse jeito inovador de aprender."

E6: "Trabalho prático muito construtivo e proveitoso. Facilita muito o entendimento teórico quando aplicado na prática, e nos mostra claramente a relação que esses conceitos tem entre si, como por exemplo: resiliência e quebra de paradigmas".

E7: "Foi possível levantar muitos aspectos. E muito proveitoso em questão didática e pessoal".

E8: "Foi algo muito proveitoso, pois partiu uma interação entre os grupos e incentivou a criatividade".

E9: "Processo de aprendizado bem proveitoso, houve ampla aprimoração do trabalho em grupo, formas de entrar em consenso, criatividade e empenho".

E10: "A atividade foi muito proveitosa, despertou nossa criatividade e fez com que o assunto abordado fosse exposto de uma forma mais simples".

E11: “Achei muito proveitosa, inovadora e divertida, a atividade realizada com a metodologia LSP”.

Figura 4 - Percepção dos Estudantes sobre a significação dos Conhecimentos.

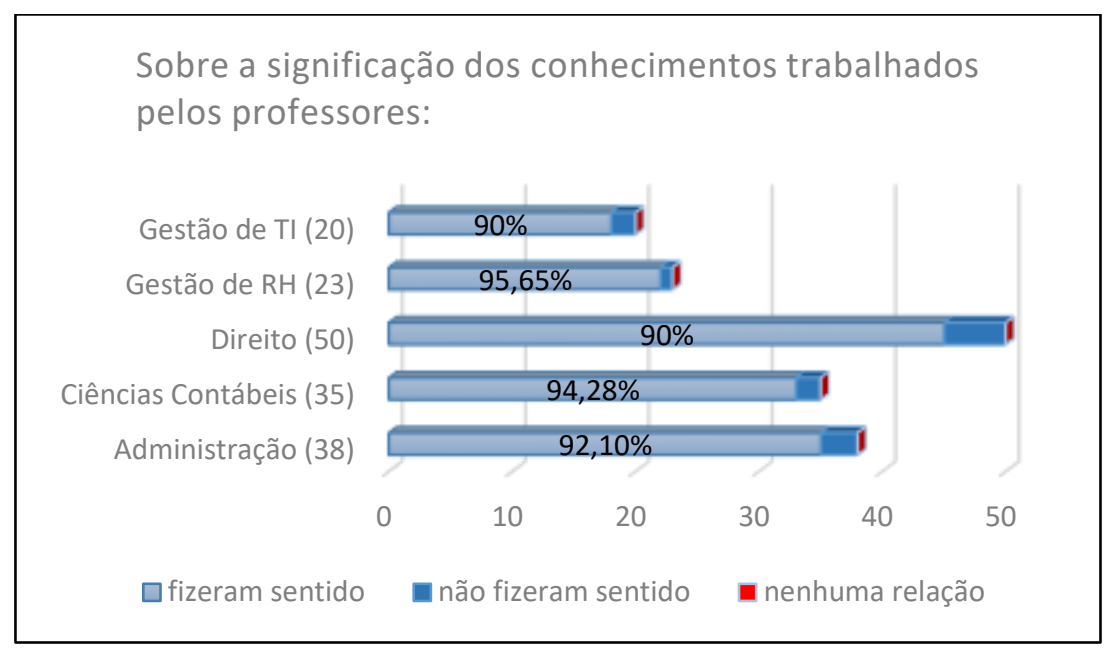

Fonte: Autores (2021).

Nota-se que, da mesma forma que a percepção na questão anterior, os estudantes tiveram uma boa receptividade por parte do método utilizado, onde foi possível por parte dos próprios estudantes perceberem a importância do que eles estavam fazendo naquele momento e como aqueles conhecimentos ali trabalhados podem ser aplicados no mundo do trabalho.

Dessa forma, a metodologia LSP aproxima-se do que segundo Ryon Braga ${ }^{8}$ denomina de modelo teático (junção das palavras teoria e prática), que se evidencia no trecho a seguir retirado da questão aberta: E11: "Fez com que aprendemos o conteúdo usando a prática e nossas próprias ideias".

Ainda conforme relatos dos docentes participantes da atividade, em suas observações perceberam os estudantes mais participativos (engajados) e com uma desenvoltura na oralidade e a maior apropriação do conteúdo estabelecido.

\footnotetext{
${ }^{8}$ Ryon Braga é Reitor do Centro Universitário Uniamérica. Graduado em Medicina pela UFPR e pós graduado em Neuropedagogia pela PUC-PR também atua com Empresário e empreendedor há 25 anos.
} 
Figura 5 - A Metodologia LSP na construção do conhecimento.

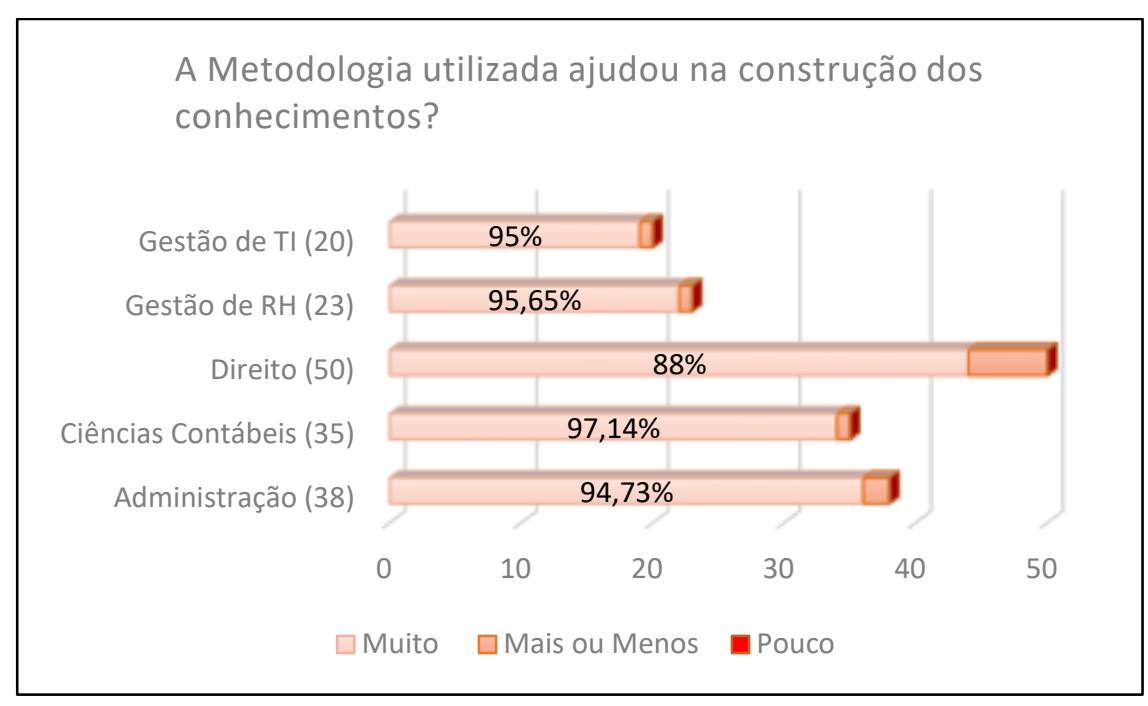

Fonte: Autores (2021).

Apesar do desconhecimento da utilização da metodologia LSP no contexto educacional, a percepção tanto dos estudantes quanto dos docentes foi positiva e ao mesmo tempo de muita surpresa com os resultados em curto prazo. A partir dos relatos docentes, onde comentaram que determinados estudantes em suas aulas regulares não demonstravam interesse ou ainda apresentavam dificuldades de se relacionar, de expressão oral e de trabalho cooperativo, na atividade proposta não eram os mesmos, o que surpreendeu os docentes. Já por parte dos estudantes, observa-se uma aceitação com base nas respostas fechadas conforme a figura 5 e na questão aberta.

E11: "Achei muito proveitosa, inovadora e divertida, a atividade realizada com a metodologia LSP".

E12: "Ótima atividade, capaz de envolver diferentes pessoas em diferentes processos e ideias, construção de conhecimento envolvido com a criatividade".

E13: "Com essas novas atividades dá para entender melhor o conteúdo e compreender melhor as empresas como funcionam".

E14: "O processo possibilitou uma interação mais efetiva com o tema estudado, já que utilizamos nosso conhecimento de forma dinâmica e atrativa. Além disso, teve espaço para trabalharmos nossa oralidade e o trabalho em equipe" 
Figura 6 - Percepção dos Estudantes quanto ao envolvimento na atividade.

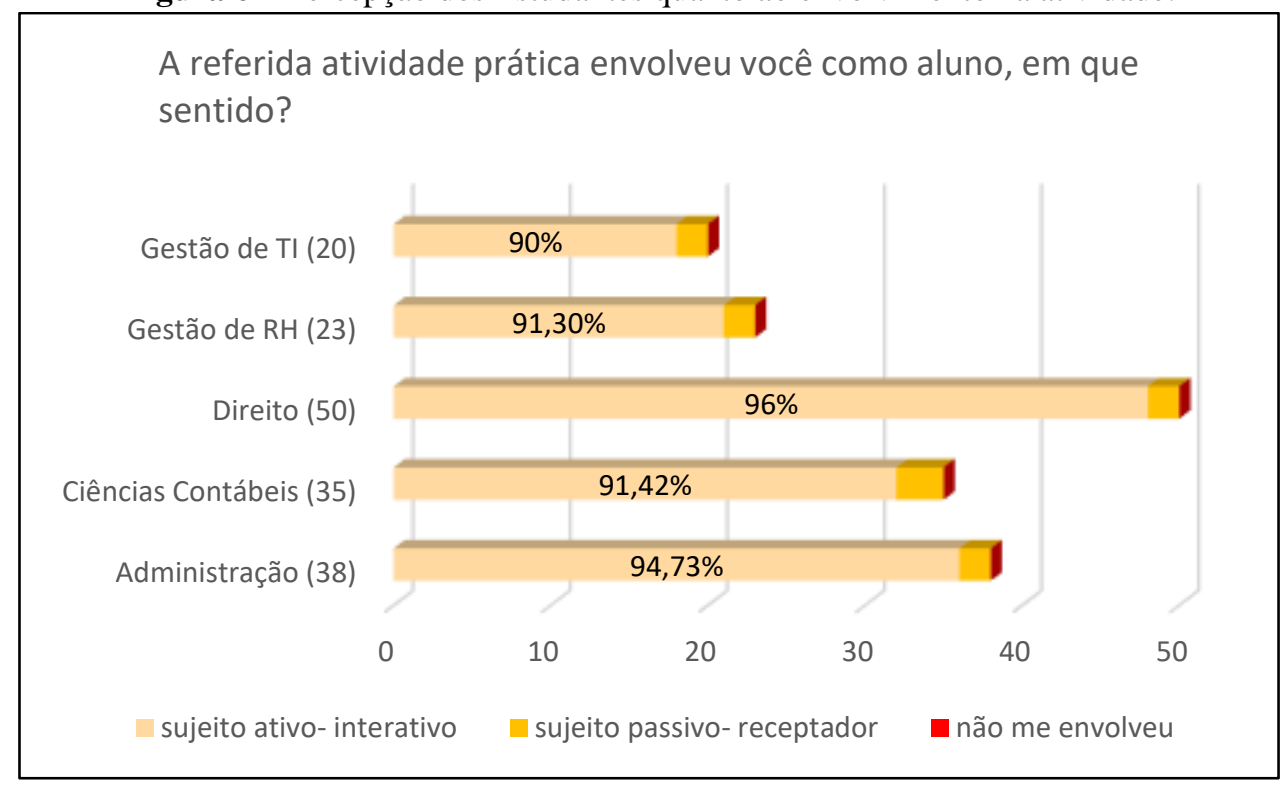

Fonte: Autores (2021).

Quanto ao envolvimento individual e pessoal (sujeito) dos 166 estudantes, 11 em suas percepções sentiram-se sujeitospassivo-receptor, o que se pode considerar um número baixo no contexto da pesquisa, quando comparados aos sujeitos-ativointerativo que é a base da proposta da metodologia LSP.

A metodologia visa o engajamento de todos 100/100 nas observações, participantes em determinados momentos havia uma dispersão quando um membro do grupo assumia a liderança e por vezes distanciava alguns estudantes da produção e compartilhamento. Observa-se que, de modo geral, 92\% sentiu-se protagonista na construção de seu saber.

A metodologia Lego ${ }^{\circledR}$ Serious Play ${ }^{\circledR}$, mostrou-se como uma estratégia inovadora no contexto dos ambientes de aprendizagem ativa, visto que, proporciona o desenvolvimento da colaboração, criatividade, permite a construção de equipes e a análise dos conteúdos e significados das representações realizadas.

É um recurso que equaliza equipes heterogêneos e facilita a integração entre professores e estudantes. A metodologia estimula, também, o pensamento sistêmico e a transdisciplinaridade, na qual o estudante precisa conhecer o 'todo', desenvolvendo uma visão panorâmica, holística e global dos fatos e dos contextos apontados no tema-problema de cada aula, o que auxilia e estimula a construção de estratégias (pessoal e profissionais) para se atingir o objetivo proposto com a máxima eficiência possível.

Por fim, resta evidente que a metodologia Lego® Serious Play® como estratégia para promover a autonomia e melhorar os resultados no processo de aprendizagem no Ensino Superior, sobretudo em ambientes de aprendizagem ativa, por meio da ludicidade neste contexto, mostrou-se de grande valia e profícuos efeitos, constatados nos resultados da pesquisa.

\section{Considerações Finais}

Destaca-se que a metodologia Lego ${ }^{\circledR}$ Serious Play ${ }^{\circledR}$ facilita o desenvolvimento de indivíduos, de equipes e de organizações, melhorando a comunicação, o pensamento e a materialização de ideias. Os processos de análise e de solução de problemas complexos também são favorecidos e promovem o aprendizado, o engajamento e o comprometimento das pessoas e potencializa seu desempenho.

Quando se pensa com as mãos, se aciona um maior número de células cerebrais para funcionar, assim as soluções tendem a chegar de forma mais rápida e criativa. Esta é a premissa principal por trás da metodologia Lego ${ }^{\circledR}$ Serious Play ${ }^{\circledR}$ 
desenvolvida em 1996 pela LEGO®, que busca estimular o uso das tradicionais peças de encaixe para encontrar soluções inovadoras a problemáticas de diversas naturezas e, assim, promover experiências de aprendizagem mais duradouras e significativas.

A metodologia Lego ${ }^{\circledR}$ Serious Play ${ }^{\circledast}$ permite, exatamente, que se crie um ambiente no qual se gere condições para que os estudantes sejam cada vez mais ativos no processo de aprendizagem, encorajando-os para este fim. Além de estimulá-los, a metodologia intenciona aguçar o senso crítico, a partir da contextualização e da conexão dos temas propostos na aula com a vida real e, por derradeiro, que os próprios aprendizes desenvolvam as soluções dos problemas abordados.

A metodologia LSP ainda é algo bastante nova no Brasil, mas tem crescido de forma rápida. Empresas como Kraft, Coca Cola, Unilever, Dupont, Google, Nasa, Toyota, Fedex e muitas outras já colhem frutos da aplicação deste método. Embora as análises preliminares dos dados do presente trabalho se mostrarem positivas, destaca-se a necessidade de estudos com maior profundidade acerca da aplicabilidade e da efetividade da metodologia Lego ${ }^{\circledR}$ Serious Play ${ }^{\circledR}$ no contexto dos ambientes de aprendizagem ativa.

De todo o exposto no estudo, depreende-se que a metodologia Lego ${ }^{\circledR}$ Serious Play ${ }^{\circledR}$ surge como uma alternativa para contribuir na melhoria dos resultados do processo de aprendizagem em ambientes e aprendizagem ativa no ensino superior. Ainda há muito o que se explorar com Lego ${ }^{\circledR}$ Serious Play ${ }^{\circledR}$, que possui grande riqueza de estímulos e diversos conhecimentos que o sustenta.

Para perspectivas futuras, pretende-se, primeiramente, trabalhar tal metodologia em formações com os docentes da Instituição, para, posteriormente, aplicar a proposta com os estudantes de outros níveis de ensino. Em sendo assim, poder-se-á verificar se as implicações e os efeitos são similares aos alcançados na presente pesquisa e, por derradeiro, avaliar os resultados por meio de uma análise com um grupo de estudantes de diferentes níveis de escolarização.

\section{Referências}

Barbier, R. (2004). A Pesquisa-ação. Líber Livro Editora.

Barbosa, E. F., \& Moura, D. G. (2014). Metodologias Ativas de Aprendizagem no Ensino de Engenharia. XIII International Conference on Engineering and Technology Education. Guimarães, Portugal.

Bergmann, J., \& Sams, A. (2017). Sala de aula invertida: uma metodologia ativa de aprendizagem. LTC.

Bürgi, P., \& Roos, J. (2003). Images of strategy. European Management Journal, 69-78.

D’ávila, C. M. (2007). Saberes docentes: um olhar sobre as práticas pedagógicas no ensino de pós-graduação. Revista entreideias, Salvador.

Filatro, A., \& Cavalcanti, C. C. (2018). Metodologias Inov-ativas na educação presencial, a distância e corporativa. Saraiva.

Fiorentini, D. (2004). Pesquisar práticas colaborativas ou pesquisar colaborativamente? In: Borba, M. C. e Araújo, J. L. (org.) Pesquisa qualitativa em Educação Matemática. Belo Horizonte: Autentica.

Gil, A. C. (2008). Métodos e Técnicas da Pesquisa Social (6a ed.), Atlas.

Hinthone, L. L., \& Schneider, K. (2012). Playing with Purpose: Using Serious Play to Enhace Participatory Development Communication in Research. International journal of Communication.

Isaksen, S. (2007). The climate for transformation: Lessons for leaders. Criativity and Innovation Management.

KAMEI, H. (2014). Flow e Psicologia Positiva. Estado de Fluxo, Motivação e Alto Desempenho. IBC.

Kristiansen, P., \& Rasmussen, R. (2015). Construindo um negócio melhor com a utilização do Método LEGO Serious Play. DVS editora.

Kristiansen, P., \& Schulte, H., \& Grienitz, I. V., \& et al. (2016). Vision Statement Development with LEGO Serious Play. Toronto University.

LEGO Group. (2002). The science of lego serious play. From www.seriousplay.com.

LEGOBRASIL. Site Oficial LEGO no Brasil. From https://www.legobrasil.com.br/.

Lopez, A. N. (2007). ¡Sera mejor que lo cuentes!: Los relatos como herramientas de comunicacion (Storytelling). (2a ed.), Empresa Activa. 
Research, Society and Development, v. 10, n. 8, e13810817164, 2021

(CC BY 4.0) | ISSN 2525-3409 | DOI: http://dx.doi.org/10.33448/rsd-v10i8.17164

Luckesi, C. (2004). Estados de consciência e atividades lúdicas. In: Porto, Bernadete. Educação e ludicidade. (3a ed.), Ensaios: UFBA.

Mccusker, S. (2014). Lego ${ }^{\circledR}$, Serious Play ${ }^{\circledR} T M^{\odot}$ : Thinking About Teaching and Learning. International journal of knowledge, innovation and entrepreneurship. $2(1), 27-37$

Minayo, M. C. S. (2002). Pesquisa Social. Ed. Vozes.

Novaes, M. A. B., Silva, E. S., Costa, M. K. R., Amorim, P. A., Machado, F. L. M., Machado, A. M. M. R., Moura, J. S., Paiva, C. R. B., Martins, I. S., Paulino, F. G. O., Araújo, M. N., Medeiros, J. L. \& André, A. S. (2021). Metodologias ativas no processo de ensino e de aprendizagem: alternativas didáticas emergentes. Research, Society and Development, 10, 1-10.

Nunes, T. (2017). O que é metodologia ou aprendizagem ativa? https://pontodidatica.com.br/metodologias-ativas-aprendizagem-ativa.

Oliveira, M. K. (1997). Vygotsky: aprendizado e desenvolvimento um processo sócio histórico. Scipione.

Papert, S. M. (2008). A Máquina das Crianças: Remarcar uma Escolinha na Era da Informática. Artes Médicas.

Papert, S. M. (1991). Construcionism. Norwood: Ablex Publishing Corporation.

Peixoto, A. G. (2016). O uso de Metodologias Ativas como Ferramenta de Potencialização da Aprendizagem de Diagramas de Caso de Uso. Periódico Científico Outras Palavras, 12(2).

Piaget, J. (1987). O Nascimento da Inteligência na Criança. (4a ed.), Editora Guanabara.

Piaget, J. (1986). Uma introdução ao Desenvolvimento Cognitivo da Criança. Editora LTC-Livros Técnicos e Científicos.

Pinto, J. B. G. (1989). Pesquisa-Ação: Detalhamento de sua sequência metodológica.

Schön, D. A. (2000). Educando o Profissional Reflexivo: um novo design para o ensino e a aprendizagem. Tradução de Roberto Cataldo Costa. Artmed.

Silva, L. S. (2018). Tudo o que você precisa Saber sobre Aprendizagem Ativa. https://www.rhacademy.com.br/single-post/2018/02/20/.

Souza, J. R. \& Silva, A. O. (2021). Fatores que interferem no processo de ensino e aprendizagem. Research, Society and Development, v.10, n.6, 1-8.

Sutherland, J. (2014). Scrum: a arte de fazer o dobro do trabalho na metade do tempo. LeYa.

Thiollent, M. (2009). Metodologia da pesquisa-ação. (17a ed.), Cortez.

Xavier, A. (2015). Storytelling - Histórias que deixam marcas. BestSeller. 